\title{
Allocation and competitiveness in the EU emissions trading scheme: policy overview
}

Michael Grubb*, Karsten Neuhoff

Faculty of Economics, Cambridge University, Sidgwick Avenue, Cambridge CB3 9DE, UK

* Corresponding author. Tel.: +44-1223-335288; fax: +44-1223-335299.

E-mail address: Michael.grubb@econ.cam.ac.uk 
Abstract: The European emissions trading scheme (EU ETS) has an efficient and effective market design that risks being undermined by three interrelated problems: the approach to allocation; the absence of a credible commitment to post-2012 continuation; and concerns about its impact on the international competitiveness of key sectors. This special issue of Climate Policy explores these three factors in depth. This policy overview summarizes key insights from the individual studies in this issue, and draws overall policy conclusions about the next round of allocations and the design of the system for the longer term.

- $\quad$ Allocations for 2008-2012. Allocations defined relative to projected 'business-as-usual' emissions should involve cutbacks for all sectors, in part to hedge against an unavoidable element of projection inflation. Additional cutbacks for the power sector could help to address distributional and legal (State aid) concerns. Benchmarking allocations, e.g. on best practice technologies, could offer important advantages: experience in different sectors and countries is needed, given their existing diversity. However, a common standard for new entrant reserves should be agreed across the EU, based on capacity or output, not on technology or fuel. Maximum use of allowed auctioning (10\%) would improve efficiency, provide reassurance, and potentially help to stabilize the system through minimum-price auctions. These measures will not preclude most participating sectors from profiting from the EU ETS during phase II. Companies can choose to scale back these potential profits to protect market share against imports and/or use the revenues to support longer term decarbonization investments, whilst auction revenues can be used creatively to support broader investments towards a low-carbon industrial sector in Europe.

- $\quad$ Post-2012 design. Effective operation during phase II requires a concrete commitment to continue the EU ETS beyond 2012 with future design addressing concerns about distribution, potential perverse incentives, and industrial competitiveness. Declining free allocation combined with greater auctioning offers the simplest solution to distributional and incentive problems. For its unilateral implementation to be sustainable under higher carbon prices over longer periods, EU ETS post-2012 design must accommodate one of three main approaches for the most energy-intensive internationally traded sectors: international (sectoral) agreements, border tax adjustments, or output-based (intensity) allocation. If significant free allocations continue, governments may also need to follow the example of monetary policy in establishing independent allocation authorities with some degree of EU coordination.

Such reform for the post-2012 period would require the Directive to be fundamentally renegotiated in relation to allocation procedures. Such renegotiation is neither feasible nor necessary for phase II operation. Rather, phase II should be a period in which diverse national approaches build experience, whilst the profits potentially accruing to participating sectors can be used to protect market share and jump-start their investments for a globally carbon-constrained future. 


\section{Introduction}

The EU emissions trading scheme was launched in 2005 to cap $\mathrm{CO}_{2}$ emissions from heavy industry. Covering almost half of all $\mathrm{EU} \mathrm{CO}_{2}$ emissions, it forms the centrepiece of European policy on climate change. Trade in these emission allowances gives value to reducing $\mathrm{CO}_{2}$ emissions and has formed a market with an asset value worth tens of billions of euros annually. Putting a price on carbon has been an achievement of global significance, through the linkages to emission credits generated under the Kyoto mechanisms: indeed, in response to the unexpectedly high prices of 2005, a flood of such projects started coming forward.

Although unprecedented in its scale and scope, the main pillars of the EU ETS were built on many years of economic research into theories of emissions trading, combined with practical experience of emission trading schemes principally in the USA. Yet the analogies are far from exact, and the emerging experience with the EU ETS is beginning to highlight the profound nature of the differences - many of which have thus far been under-appreciated in economic and policy analysis.

Like any market, the key to prices is scarcity, and the price depends on both the absolute quantity of allowances available and expectations about the future. The most fundamental difference of emissions trading from any normal market is that the amount available depends directly on government decisions about allocations; and expectations about the future are largely expectations about future emission targets. The large price drop of EU ETS prices in Spring 2006 is the first tangible sign of the scale of the problems around allocation in the EU ETS. Equally, some of the initial responses give a foretaste of numerous other possible problems: 
- $\quad$ Suggestions to 'bank’ surplus allowances forward into phase II (the Kyoto first period), without understanding and correcting the cause of the initial problem, may simply exacerbate similar problems in the next, crucial, Kyoto phase;

- $\quad$ Plans to withdraw allowances from the market risk being seen as penalizing abatement. Indeed such ex-post adjustment runs the risk of undermining the basis of a stable market upon which industry feels confident to invest;

- $\quad$ Proposals to use 2005 as the base year for phase II allocation risk a perverse 'updating' incentive; a belief that higher emissions today will be rewarded with bigger allocations in future periods.

Due in part to the sheer scale of the EU ETS, governments are subject to intense lobbying relating to the distributional impact of the scheme, and are constrained by this and by concerns about the impact of the system on industrial competitiveness. Few academics understand the real difficulties that policy-makers face when confronted with economically important industries claiming that government policy risks putting them at a disadvantage relative to competitors. Yet attempts to manage the consequences - by giving allocations based on projected needs, by ex-post adjustments after the real situation becomes clearer, or by updating allocations based on most recent data - are loaded with the potential to weaken the system with perverse incentives that undermine the original objective. The same is true of many other 'fixes' to meet the pressures of lobbying and competitiveness concerns. Allocation is at the heart of the EU ETS; it is also potentially its Achilles heel.

This Special Issue brings together the most complete analyses of these core issues yet conducted: 
- $\quad$ Three articles apply economic modelling to focus directly upon how the EU ETS and allocation decisions may affect sector profits, pricing, market share and incentives: an overview study of five key sectors, complemented by finer-grained modelling of the electricity and cement sectors, to study the incentive aspects of different allocation approaches.

- $\quad$ Three articles look at issues arising from these economic consequences of the EU ETS. One study presents initial empirical evidence about the system's impact on electricity prices and profits. A legal study highlights how the scale of profits generated under the ETS may itself bring contrary pressures to bear on the allocation process through State-aid considerations. Both of these then inform an analysis of the issues surrounding auctioning of emission allowances, including the extent to which auctioning might help to address some of the difficulties identified in other articles.

This overview also draws on several other studies, including a related analysis of how the modelling studies of aggregate sectors 'in equilibrium' relate to the diverse nature of key sectors across Europe, and the likely dynamics of economic impacts and mitigation potentials over time (Grubb et al., 2006).

This policy overview is in two parts. Part A draws directly on these component studies to clarify and emphasize five ways in which the EU ETS differs from previous emissions trading system.

1. The economic scale of the scheme, which drives heavy lobbying around allocation and competitiveness concerns, yet which paradoxically is the source of profit-making incentives unprecedented in the history of environmental policy; 
2. The consequently small nature of cutbacks relative to 'business-as-usual' and the resulting instabilities in the system;

3. The corresponding large proportion of free allocation, which underlies legal stresses and the scope for distortions;

4. The multi-period nature of allocations, which drives dependence both upon post-2012 decisions and the risk of perverse incentives;

5. The devolution of allocation responsibilities to Member States and the way this affects the development of viable solutions.

Part B then examines the 'bigger picture' policy implications that flow from this: the implications for allocation during phase II; the options for longer-term continuation; and the implications in terms of the existing Directive and related institutional considerations.

\section{Part A: Why the EU ETS is different - and what that implies}

\section{A1. Scale, costs and competitiveness}

In terms of economic scale, the European emission trading scheme is the biggest such scheme in the world by an order of magnitude. At allowances prices in the range €10$30 / \mathrm{CO}_{2}$, the value of allowances issued every year is $€ 22-66$ billion, compared with the USA's East Coast NOx trading programmes ( $€ 1.1$ billion) or $\mathrm{SO}_{2}$ trading schemes (€2.8-8.7 billion). ${ }^{1}$ The sheer scale of the EU ETS means that it could affect the costs of key industrial sectors more than any previous environmental policy - perhaps more than all the others put together. Yet part of the problem in the debate over the EU ETS 
is the tendency to make sweeping generalizations, not least about costs and competitiveness impacts.

Two aspects drive competitiveness issues. First, the level of international competition for a specific product and, second, the direct and indirect $\mathrm{CO}_{2}$ emissions associated with the production. Figure 1 provides a sense of scale for both dimensions.

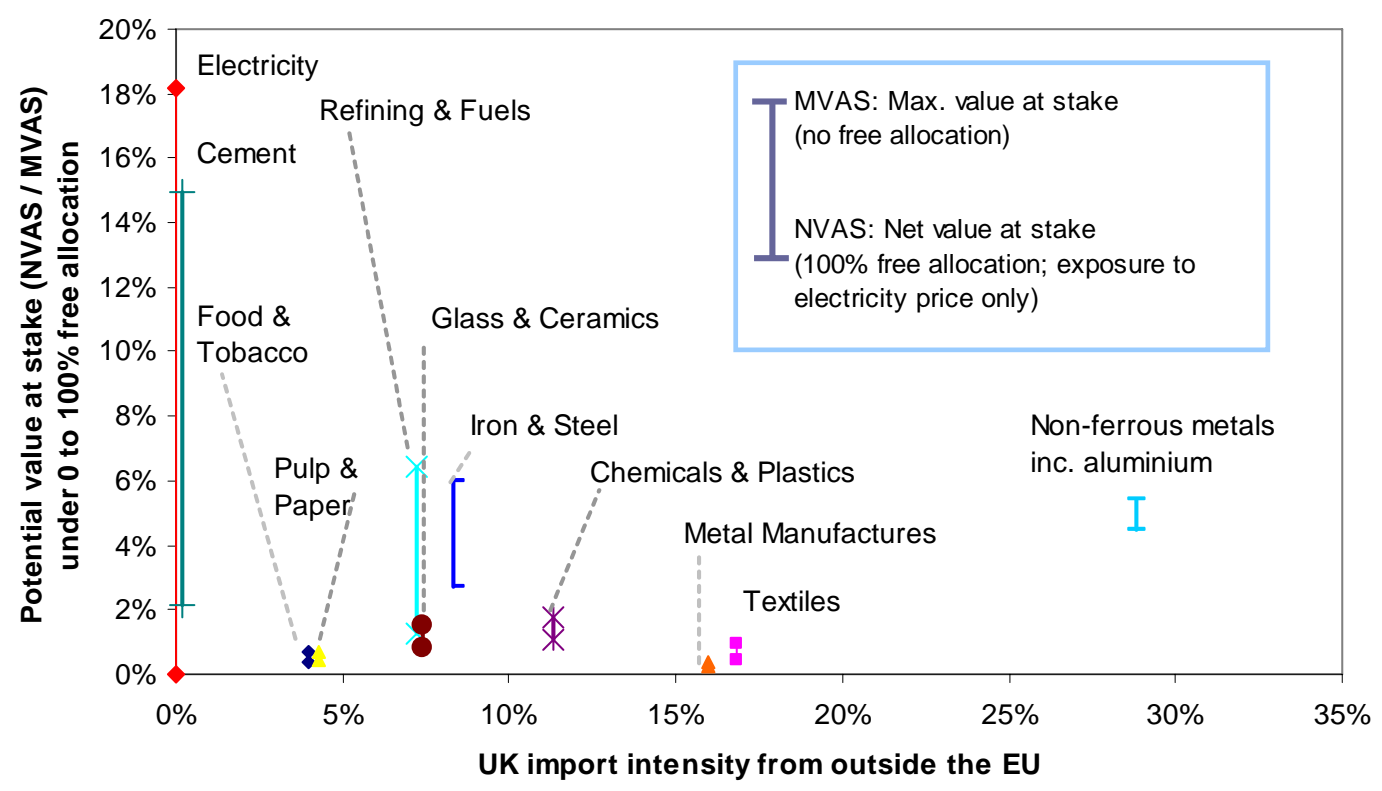

Figure 1 - Value at stake over range $0-100 \%$ free allocation, relative to UK trade intensity from outside the EU. The chart shows results for a carbon price of $€ 15 / \mathrm{tCO} 2$ and an electricity cost pass-through resulting in wholesale electricity cost increase of $€ 10 / M W h$. Scaling the electricity price would move the lower point of the bars in proportion; scaling the carbon price would scale the length of each bar in proportion. Source: Grubb et al. (2006).

As an indicator for the cost exposure, the vertical axis of Figure 1 depicts the potential value at stake for major industrial sectors. It is defined as the potential impact of the EU ETS on input costs relative to sector value-added, before any mitigation or passthrough of costs onto product prices. The horizontal axis shows the current trade exposure of these sectors. The data are for the UK, which in many respects is one of the most exposed countries in Europe to external trade effects, and in which most 
sectors (with the exception of pulp and paper) are plausibly representative of the situation facing many European producers.

The lower end of the vertical bars shows the net value at stake (NVAS) if the sector participates in the EU ETS and receives free allocations equal to its 'business-asusual' emissions, takes no abatement action, and does not change product prices: the NVAS then represents the sector's exposure to indirect costs through electricity price impacts only, since all direct emission costs are covered by free allocations. The most striking feature of the graph is that only three sectors have NVAS exceeding $1.5 \%$ of sector value-added. If exposed to the full impact of electricity price rises, NVAS is estimated at $2.1 \%$ for Cement, $2.7 \%$ for Iron and Steel, and finally $4.4 \%$ for Nonferrous Metals (principally aluminium).

Box 1: Five principles underlying the economic impacts of emissions trading The aim of emissions cap-and-trade is to secure emission reductions at the lowest possible overall cost: the trading allows companies to seek emission reductions to meet the aggregate cap wherever and however it is cheapest to do so. Five principles underlie the practical economic impact of an emissions trading system applied to $\mathrm{CO}_{2}$ :

1. In general, $\mathrm{CO}_{2}$ constraints generate economic rents, and free allocation of allowances to industry gives the potential to capture this value and profit, subject to:

(a) degree of alignment of allowances with costs (e.g. not sectors outside EU ETS or affected primarily by electricity pass-through costs);

(b) constraints on cost pass-through due to imports and other factors. 2. Profit and market share are not synonymous, and for internationally traded goods they are frequently in opposition: the more that companies profit by raising prices to reflect the opportunity costs of carbon, the greater the possible erosion of their market share over time.

3. The details of allocation methods matter: new entrant, closure, and incumbent allocation rules all affect the incentives, pricing and efficiency of the scheme.

4. The power sector can and does pass through the bulk of marginal/opportunity $\mathrm{CO}_{2}$ - related costs to the wholesale power markets, as expected in a competitive system, resulting in substantial profits and downstream costs where retail markets are competitive.

5. Other participating sectors also have the potential to profit in similar ways, but the net impact is complicated by details of electricity retail market regulation, by international trade, and by downstream company, regional and product differentiation. 
The high value attributed to non-ferrous metals reflects dependence on electrical input for processes, particularly for aluminium, which sometimes result in it being termed 'solid electricity'. ${ }^{2}$ For cement, iron and steel, the figure is around 2\%; refining, which uses hardly any electricity from the grid and has NVAS with $100 \%$ free allocation, is $1.3 \%$ of its total value-added. The pulp and paper sector does not have significant cost exposure in the UK, although other EU producers may have. The impacts could be non-trivial for a few other individual subsectors - notably in glass and ceramics, and in chemicals, both of which have average sector NVAS exposure at $100 \%$ free-allocation, close to $1 \%$ of value-added. In all cases, the actual net impact depends on the extent that industries can undertake cost-effective emissions abatement measures or pass on $\mathrm{CO}_{2}$-related costs to product prices.

The upper end of the bars shows the theoretical impact on sectors in the EU ETS if there were no free allocations - equivalent to $100 \%$ purchase (on markets or through auctioning at the market price). This forms a potential maximum value at stake (MVAS) that would arise from such allocation, or an equivalent carbon tax, if product prices were held constant and no abatement undertaken.

The significance of the upper level (no free allocation) is that it also gives an indication of the impact on marginal/opportunity cost for producing an additional unit of output. ${ }^{3}$ As long as increasing or decreasing production does not change the amount of free allowance allocation, the incremental decision to produce more (or less) faces the full cost of extra allowances (or the opportunity cost of not selling allowances). Thus the upper end of the bars gives a rough indication of the potential relative impact on output prices, if firms pass through these opportunity costs. As discussed below, such pricing can lead to large profit gains from the EU ETS. 
However, passing through the opportunity cost impacts of the EU ETS would increase prices relative to imports from regions outside the EU ETS. ${ }^{4}$ This forms the main constraint on the ability to pass $\mathrm{CO}_{2}$-related costs on to customers. The chart also shows (horizontal axis) the existing degree of imports from outside the EU. The quite exceptional position of aluminium, as noted in Smale et al. (2006), is readily apparent - not only is its NVAS potentially twice that of any other sector, but the same is true of its import intensity.

In contrast, hardly any cement is currently imported from outside the EU. This does not imply that changes in production costs cannot create opportunities for international trade. Its maximum value at stake (MVAS) - and the relative significance associated with marginal/opportunity cost pricing - is comparable with electricity itself, at more than twice that of any other sector. This explains the high leakage rate associated with profit-maximization mentioned in Demailly and Quirion (this Issue): if the sector passes through most of its marginal/ opportunity costs, the price differential simply becomes so large as to overcome the barriers that have traditionally kept foreign imports out.

The equivalent MVAS impact on refining and fuels, and iron and steel, is about 6\% each and both have existing trade intensity around 7-8\%. For the UK, no other sector in aggregate has marginal value-at-stake impacts above $2 \%$, even for zero free allocation.

Several points flow from this. Allocation and competitiveness in the EU ETS is a tale about a few key sectors. At the prices and allocations plausible in phase II (considered briefly below) the net cost impacts are not large relative to sector value-added. If impacts on marginal costs were passed through to prices, while the sectors still receive mostly free allocations, as detailed below the sectors will profit substantially 
but with an erosion of international competitiveness over time. Moreover, differences in allocations between Member States would affect the cash flows of their companies (the length of the vertical bars gives an indication of sensitivity to this), and many have far greater trade within Europe than outside it (discussed further in Grubb et al., 2006, which presents equivalent data for trade within the EU). In reality these internal dimensions do far more to drive lobbying and allocation decisions than the external competitiveness considerations, and we now turn to consider some consequences.

\section{A2. Small cutbacks and price instabilities}

The scale of the EU ETS, combined with the relative difficulty of reducing $\mathrm{CO}_{2}$ emissions compared to many other pollutants, has two immediate consequences: cutbacks imposed in phase I - and under discussion for phase II - have been small; and prices have been volatile. Cutbacks in phase I of EU ETS amounted to about 1\% of projected needs, contrasting, for example, with the US $\mathrm{SO}_{2}$ programme, which involved cutbacks over $50 \%$ of historical emissions, and additional reductions later. 


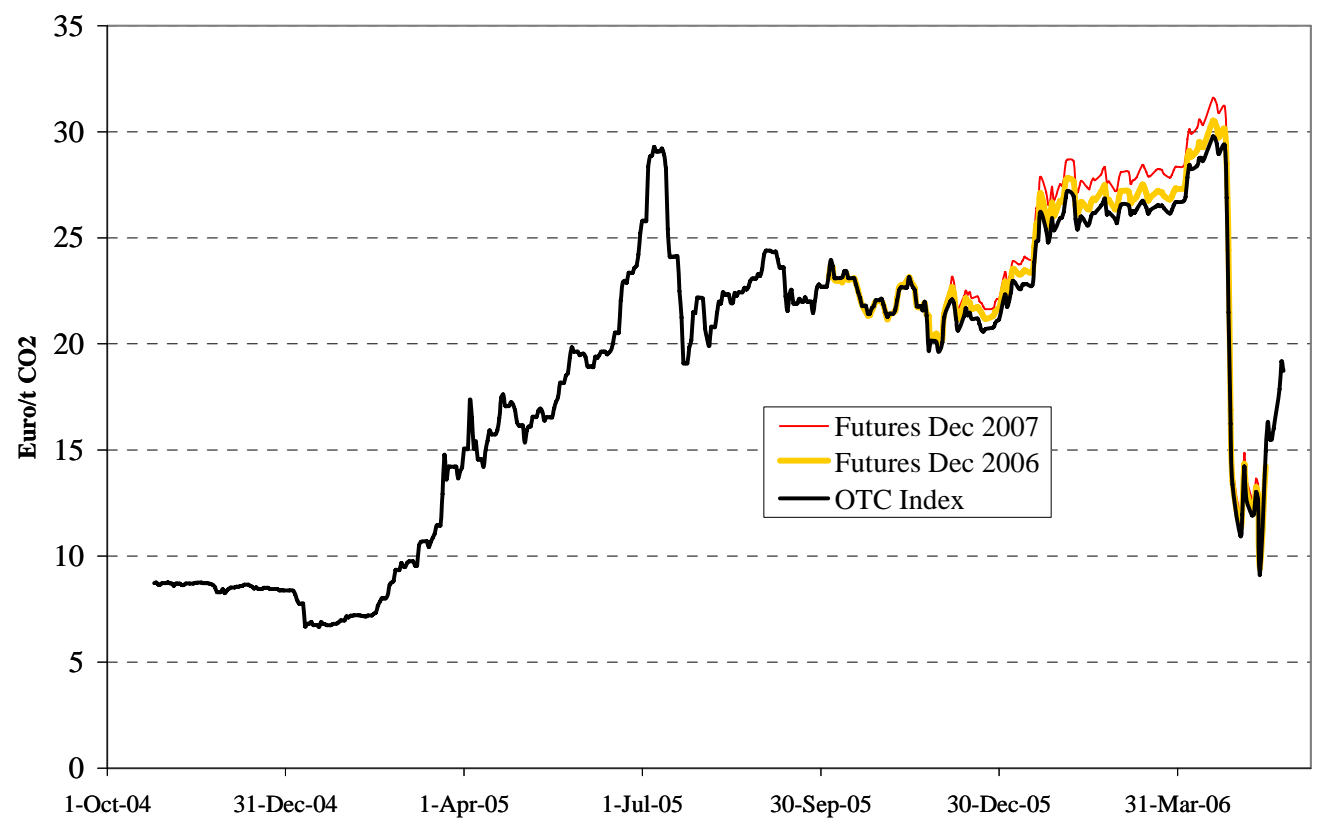

Figure 2 - EU ETS trading prices from Oct 2004 to May 2006. Source: European Energy Exchange.

The evolution of prices is illustrated in Figure 2. In the few months after its launch, prices, initially around $€ 10 / \mathrm{tCO}_{2}$, rose to unexpectedly high levels. This was due to two main factors: European Commission resistance to larger allocations in some outstanding disputes with Member States; and soaring gas prices that drove electricity production back to coal and raised the $\mathrm{CO}_{2}$ price that would be required to reverse this. After tracking the coal-gas price differential up to close to $€ 30 / \mathrm{tCO}_{2}$, prices decoupled from gas prices and varied in the range $€ 20-30 / \mathrm{tCO}_{2}$, as generators focused on other opportunities (e.g. brown coal to hard coal), before crashing in Spring 2006. The price crash occurred as data on actual 2005 verified emissions were released, and this displays the extreme sensitivity arising from the small cutbacks of EU ETS allocations. Figure 3 shows the actual emissions, ${ }^{5}$ compared to the corresponding initial allocations, and a few different estimates made by market analysed. Even as late as Spring 2006, there were retrospective estimates from a leading provider of 
market intelligence that turned out to be completely wrong. The uncertainty in projections upon which NAPs had originally been based was, of course, far wider. Some excess of allocations over verified emissions, which led to the large price reductions, was predictable. ${ }^{6}$ Moreover, as indicated, the higher gas prices shifted some power generation back from gas to coal-based operation, increasing emissions compared to initial power sector projections. Thus the error, and the excess of allocations, could easily have been bigger, and was in most other sectors. Both evidence and theory suggest that projection-based targets and allocations tend to be biased upwards. $^{7}$

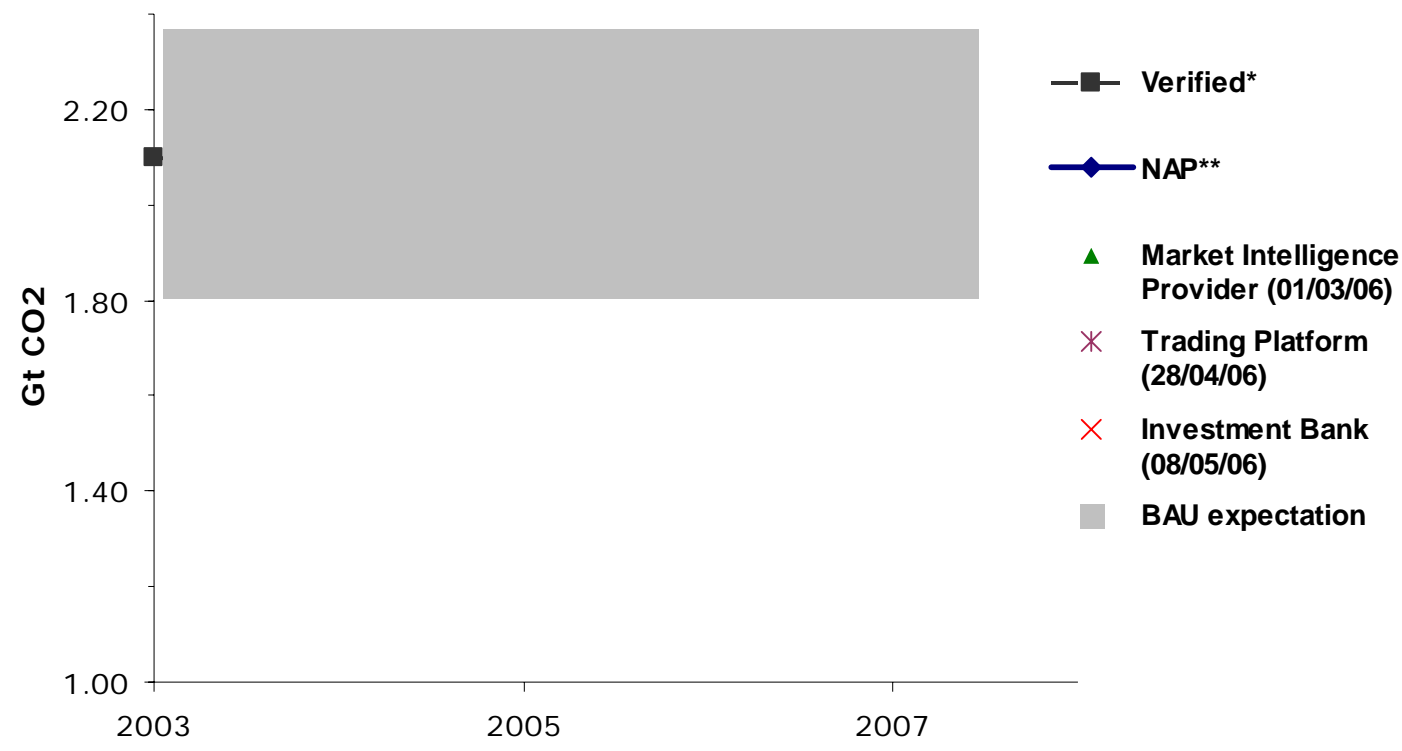

Figure 3 - Uncertainty on emissions from installations covered by the EU ETS.

The key difference between the EU ETS and other trading programmes is that the cutbacks negotiated have been well within the range of projection uncertainty. This inevitably creates price volatility if, as has been the case before, emissions turn out to be lower than the projected basis upon which allocations are made.

Price volatility carries a cost. Difficulties in predicting future allowance prices are delaying investment decisions. By waiting, a company can gain more knowledge 
about future $\mathrm{CO}_{2}$ prices, and thereby make better decisions. Furthermore, in the presence of price uncertainty, risk aversion is also likely to reduce investment. ${ }^{8}$ The risk of low $\mathrm{CO}_{2}$ prices represents a significant hurdle for low-carbon investments. Obviously, companies are prepared to bear risks, but they generally prefer to take risks in their core business, where the additional management attention can at the same time create strategic opportunities.

As indicated in the Introduction, most of the immediate responses to the price crash threaten cures which may be worse than the problem, because of the way they undermine the integrity of the market or introduce perverse incentives. Clearly, given relatively modest cutbacks in the face of large uncertainties, policies which can provide a greater degree of price stability in the EU ETS would be valuable. ${ }^{9}$ Options considered in this Special Issue (by Hepburn et al., 2006) include the use of 'active auctioning'.

\section{A3. Potential over-compensation and profit-making}

A third and related feature is the tendency towards 'overcompensation'. $\mathrm{CO}_{2}$ costs feed into production costs. The normal response to higher input costs is to raise product prices to compensate. Economically, free allocation amounts to an alternative way of compensating - or protecting - companies from the costs of carbon.

Firms in reasonably competitive markets maximize profits by setting prices relative to marginal cost of production. These marginal costs now include opportunity costs of $\mathrm{CO}_{2}$ allowances, even if allowances are received for free - in which case there is potential 'double compensation'. This creates the potential to make substantial profits, as found in the modelling studies in this Issue by Smale et al. (2006), and 
analysed more fully for electricity by Sijm et al. (2006) and for cement by Demailly and Quirion (2006).

The empirical situation is mixed (Sijm et al., 2006). In countries with liberalized power markets, generators have passed through most of the opportunity costs, as expected, with aggregate profits totalling billions of euros. There are notable exceptions, including France and Spain, where the retail price levels are set by government contracts or regulation. ${ }^{10}$ However, whilst consumers may welcome such protection from the real costs of $\mathrm{CO}_{2}$, all these approaches create distortions that can prevent entry from third parties and undermine the attendant incentives for companies to reduce $\mathrm{CO}_{2}$ emissions and for consumers to reduce electricity consumption. In other sectors, pricing responses may be influenced by competition from outside Europe. This is not an 'all or nothing' constraint: if firms maximize profits, they will still generally pass through much of the opportunity cost, making profits at the risk of some loss of market share (Smale et al., 2006). Granting free allocations is thus highly imperfect as a protection against foreign competition: companies still face the full costs in their marginal production decisions. In most products, the price rise required to recoup the net exposure (NVAS) alone is trivial (Carbon Trust, 2004; Grubb et al., 2006); the marginal cost incentive is to go beyond this, and end up both making profits from the system and losing some market share.

The more robust justification for free allocation is that it compensates existing assets for the impact of environmental regulation that was not foreseen at the time of construction. This interpretation would create clear criteria for the amount and basis for allocation, and indicate that free allocation is part of a transitional process towards a strategic objective of fully internalizing $\mathrm{CO}_{2}$ costs. 
Free allocation of allowances probably qualifies as State aid under the State Aids Directive (Johnston, 2006). Countries may thus have to make State aid declarations (otherwise, allocations could be challenged in national courts). State aid could be justified as a compensation for forgone profits due to the environmental regulation, but in this situation the proportionality principle applies - the amount of State aid should be proportional to the forgone profit. To the extent that profits may be deemed to amount to excessive compensation, this may create considerable legal pressures to reduce the scale of free allocations.

Free allocation can distort incentives. If installations cease to receive free allowances when they close, the withdrawal of over-compensation creates a perverse incentive to keep inefficient facilities operational.

If the objective of free allocation is to compensate existing assets for the impact of new regulation, it should not be required for new entrants. In practice, most governments set aside free 'new entrant reserves', which economically amount to an investment subsidy. If the volume were unlimited, such subsidies might reduce the product price - which may be part of the aim, but is not actually achieved. ${ }^{11}$ Governments use NERs to help support new construction, but giving free allowances in proportion to the carbon intensity of new plants, can bias the incentive towards more carbon-intensive investments (Neuhoff et al., 2006). When projected forwards, such distortions are amplified by the multi-period nature of the EU ETS, to which we now turn.

\section{A4. The multi-period nature of the EU ETS}

The repeated negotiations of allocations for subsequent periods create additional challenges for the European emission trading scheme. $\mathrm{CO}_{2}$ budgets and allowance 
allocations are only determined for a limited time period, initially 3 and 5 years. Even beyond 2012, the need for flexibility to adapt to learning in both climate change science and mitigation may make it difficult to commit credibly to much longer allocation periods. The complications of international negotiations put further constraints on such commitments.

As indicated above (and see note 9), uncertainty about the future carries a cost, and early clarity about post-2012 continuation would be valuable. The rules surrounding future allocations, however, need to address a number of issues arising from the potential incentives surrounding multi-period allocations.

In negotiating allocation plans for future periods, governments will inevitably find it hard to ignore the latest information on emissions. For example, upon releasing the verified emissions data for 2005, the European Commission suggested that these should be considered in allocation plans for the period 2008-2012. Yet, such ‘updating’ creates a potential problem, sometimes known as the ‘early action problem': if free allocations continue and industries expect future allocations to reflect recent emissions, this undermines the incentive to reduce emissions now. This is the strongest case of the 'updating' problem. In fact, there are a range of periodic allocation options which introduce different degrees of perverse incentives, as illustrated in a ‘triangle of potential distortions' (Table 1, also see Neuhoff et al., 2006). This illustrates how the distortions increase when moving from auctions (top) to allowance allocation based on historic emissions (bottom). With equal allowances allocated per unit of installed capacity (uniform benchmark, capacity-based), then only the closure of inefficient plants is discouraged. ${ }^{12}$ The distortion is much stronger if the allocation differs according to fuel type or production process, so that higheremitting plant types (per unit output) get more allowances. These incentives refer to 
incumbents, but if the previous period's new entrants expect to receive the same free allocations as incumbents in subsequent periods, these distortions may transfer to the actual investment decision, with the potential for particularly perverse consequences. ${ }^{13}$ Allocating allowances in relation to historic production (e.g. of electricity) creates additional distortions, this time in relation to plant operation and pricing. ${ }^{14}$

\begin{tabular}{|c|c|c|c|c|c|c|}
\hline & & $\begin{array}{l}\stackrel{\mathscr{U}}{\tilde{U}} \\
\stackrel{\Xi}{\Xi}\end{array}$ & $\begin{array}{l}\text { More expen } \\
\text { extending p } \\
\text { potential mi } \\
\text { relative to } \mathrm{n}\end{array}$ & $\begin{array}{l}\text { diture on } \\
\text { lant life (and } \\
\text { nimum-run) } \\
\text { ew build }\end{array}$ & $\begin{array}{l}\text { Increase } \\
\text { operation } \\
\text { of higher } \\
\text { emitting } \\
\text { plants }\end{array}$ & $\begin{array}{l}\text { Less energy } \\
\text { efficiency } \\
\text { investments }\end{array}$ \\
\hline $\begin{array}{l}\text { Allowance all } \\
\text { method }\end{array}$ & cation & 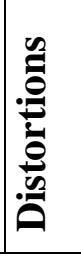 & $\begin{array}{l}\text { Discourage } \\
\text { plant } \\
\text { closure }\end{array}$ & $\begin{array}{l}\text { Discourage } \\
\text { closure of } \\
\text { higher } \\
\text { emitting } \\
\text { plants }\end{array}$ & $\begin{array}{l}\mathrm{CO}_{2-} \\
\text { inefficient } \\
\text { fuel choice } \\
\text { and plant } \\
\text { operation }\end{array}$ & $\begin{array}{l}\text { Reduce } \\
\text { incentives } \\
\text { for energy } \\
\text { efficiency } \\
\text { investments }\end{array}$ \\
\hline Auction & & & & & & \\
\hline Benchmarking & $\begin{array}{l}\text { Capaci } \\
\text { only }\end{array}$ & & $\mathrm{X}$ & & & \\
\hline & $\begin{array}{l}\text { Capaci } \\
\text { plant ty }\end{array}$ & $\begin{array}{l}\text { y by } \\
\text { pe }\end{array}$ & $\mathrm{X}$ & $\mathrm{X}$ & & \\
\hline Updating from & Output & only & $\mathrm{X}$ & $X$ & & \\
\hline periods & $\begin{array}{l}\text { Output } \\
\text { plant ty }\end{array}$ & & $\mathrm{X}$ & $X$ & $\mathrm{X}$ & \\
\hline & Emissi & & $\mathrm{X}$ & $\mathrm{X}$ & $\mathrm{X}$ & $\mathrm{X}$ \\
\hline
\end{tabular}

Table 1 - Effect of allocation methods to power sector incumbents

Phase I allocations were, and phase II are expected to be, mainly related to historic $\mathrm{CO}_{2}$ emissions. If companies expect a continuation of this approach, then in addition to the above distortions, the incentive for companies to improve the energy efficiency of existing or new plants is reduced. 
All these effects are created by the expectations about allocation for the period post2012. Committing to less distortionary methods would reduce adverse impacts, and starting to use such approaches during phase II would make this more credible. All distortions can be reduced if governments credibly commit to reducing the free allowance allocation related to historic data or existence of installation.

Note that these incentives apply to methodologies at facility level. Where countries separate aggregate emission allocations from the way they are distributed between facilities, the incentive effects need to be distinguished. For example, taking account of recent emissions in setting aggregate national or sector caps may introduce no operational distortions if the allocations to individual facilities are done on an entirely different basis - but the disjuncture may exacerbate distributional tensions. Finally, some of the potential difficulties in allocation are exacerbated by the lack of harmonization, if a sector in one country can plausibly argue that the methodology adopted in another is more favourable. We now consider this final characteristic of the EU ETS.

\section{A5. Devolution of allocation responsibilities}

The final way in which the EU ETS differs from many other trading systems is in the devolution of allocation responsibilities, in this case to its 25 Member States. This was an essential part of the deal that enabled the adoption of the Directive: Member States would never have ceded to the European Commission the power to distribute valuable assets to their industries. Nor is the EU ETS unique in devolving powers of allocation: it is typical in a number of US systems. Moreover, there are different degrees of harmonization, applicable to different aspects of the EU ETS, and the 
Commission can and does seek to increase the degree of harmonization through guidance notes (del Rio Gonzales, 2006).

Nevertheless, the devolution of allocation responsibilities does cause significant problems. The most notable area is with respect to new-entrant rules, where free allocation might be interpreted as a subsidy of new investments. This immediately raises the prospect of a 'race to the bottom' as Member States compete to attract investment.

In practice, competition on broader aspects of the allocation method to incumbents is also problematic. Politics is largely comparative, and claims by one company or sector that it is being treated more severely than its neighbour can create powerful pressures to weaken allocations. If companies can use recent operational data or projected activities to buttress their case for more generous allocations relative to neighbours, this starts to introduce perverse incentives based around efforts to prove why one’s own industry is bound to emit more than neighbouring ones. Significant differences between Member States in allocation and expectations can amplify some of the incentive problems indicated above. The European Commission does not have the legal authority to scrutinize allocation at this level beyond the remit of explicit State-aid considerations.

A sense of proportion is vital in this context. The height of the bars in Figure 1 gives a sense of the real sensitivities to allocation differentials. At a carbon price of $€ 15 / \mathrm{tCO}_{2}$, a 5\% differential allocation in the iron and steel, or refining and fuels, sectors would represent just $0.25 \%$ change in the sector 'value-added'. Only in cement and electricity could the value of a $5 \%$ allocation differential potentially approach $1 \%$ of value-added; in both cases, this is also small compared with existing price differentials between different parts of Europe, because of transport costs, and tie-line 
constraints and losses, respectively. Comparative lobbying, and the case for harmonization, needs to be kept in this context.

\section{Part B: The policy implications}

During 2006, the EU emissions trading scheme faces practical decisions in two key areas. The first is the allocation plans for the first Kyoto period of 2008-2012. The second is the conduct of a major review, to lay out options for continuing the system post-2012, and to signal how the Directive may evolve in that context. This part of the article addresses these two dimensions.

Considering post-2012 design may appear to be premature, but is likely to be just as important as getting phase II right. Investment decisions now hinge on projected revenue streams out to well beyond 2012; therefore, the decision, nature, and indeed location, of investment in the case of highly tradable goods, may be as much influenced by post-2012 expectations as by phase II allocations. Operational decisions may be distorted to the extent that operators believe that current emissions may influence future allocations. The price of allowances during phase II will be influenced by expectations about the future, both indirectly and directly, because allowances can be banked into the post-2012 period.

Thus the two dimensions are linked. We start by looking at phase II allocations, then address post-2012 options, and conclude by considering linkages and cross-cutting institutional issues. We do not discuss various dimensions already extensively covered in other studies or ongoing processes, such as: ${ }^{15}$

- $\quad$ technical aspects of implementation, accounting rules, financial reporting standards 
- $\quad$ extension of ETS to cover other sectors, both within industry and others such as transport $^{16}$

- $\quad$ the small installation limit, notably the debate about whether the present 20 MW threshold should be raised in order to reduce transaction costs. ${ }^{17}$

These are important issues, but our focus is upon allocation and competitiveness, and associated issues around price.

\section{B1. Allocation for phase II}

\section{The context for phase II allocations: the international dimension}

With the Directive as it stands, the allocation method is entirely in the hands of Member States, subject to the constraint that governments must give at least $90 \%$ of allowances out for free and respect the relevant criteria under the EU ETS Directive. Unlike phase I, they will, however, be making decisions in the context of Kyoto commitments, and using experience from phase I. This involves the knowledge that in countries with competitive markets, the power and potentially other sectors have been profiting from their free allowance allocation. Forecasts for most sectors, particularly outside electricity, have been revealed to have an upward bias, consistent with previous experience of allocation-related negotiations. The sensitivity of power sector emissions to gas prices increased the volatility of $\mathrm{CO}_{2}$ prices, and this linkage is unlikely to vanish in the coming years.

This suggests that the expected balance of supply and demand, and associated uncertainties, should be an important consideration for phase II NAPs. This must include the potential for credits generated internationally through the Kyoto Protocol mechanisms. The high ETS prices in 2005 led to a surge of investment in projects 
intended to generate emission reduction credits, particularly through emissionreducing investments in developing countries under the Clean Development Mechanism (CDM). As of March 2006, the projects officially registered or submitted for verification or registration would generate some $825 \mathrm{Mt} \mathrm{CO}_{2}$-equivalent up to 2012. Box 2 sets out international projections, which indicate a scale of external supply of Kyoto units that would be looking for buyers. This on its own makes sustained high prices during the phase II of the EU ETS period implausible. 


\section{Box 2. International Supply and Demand of Emission Credits and Allowances}

International supply projections. Especially with the recent collapse of prices, it is likely that some projects already submitted may not proceed, but the majority are already substantially developed, and of course many more could yet be submitted. Estimates of likely credits available through the CDM range from 680 to $1200 \mathrm{MtCO}_{2}$. Then there are Joint Implementation (JI) projects in Eastern Europe, for which the range is more uncertain because the institutional processes only came into being in December 2005; estimates from a Climate Strategies workshop spanned 120 to $980 \mathrm{MtCO}_{2}$ over the Kyoto first period. The combined projections are a little lower than those of one of the major market analysts, PointCarbon, who project total project credit supply to be $1000-3000 \mathrm{MtCO}_{2}$ (see Table below).

International demand and surplus Kyoto allowances. The lowest estimate is comparable to the possible demand from Japan; Canada could also compete but with less certainty. These numbers, however, do not include the supply of surplus Kyoto Allowances available from the Eastern European economies without the need for specific projects: the total potentially available is several thousand $\mathrm{MtCO}_{2}$ (3000-8000). Thus the Kyoto system has a supply of project-based credits already in the pipeline (officially or unofficially) that are likely to considerably exceed non-EU demand, plus a large 'buffer' of surplus Kyoto allowances potentially available. This will inevitably tend to depress the price during the Kyoto period.

\section{Estimates of volume of emission credits available through the international system}

Cumulative $\mathrm{MtCO}_{2}$ to 2012

\section{SUPPLY}

CC-Perspectives/Climate Strategies estimates (a)

Clean Development Mechanism (CERS)

Joint Implementation (ERUs)

LOW

$\mathrm{HIGH}$

Total emission credits

PointCarbon estimates (b)

1000

3000

Potential supply of surplus Assigned

Amounts

\section{NON-EU SOURCES OF DEMAND}

Japan

(Canada*)

$(700)^{*}$

$(1300)^{*}$

(a) CDM estimates by CC-Perspectives based upon registered projects; CDM and JI estimates debated and adjusted for likely attrition through the registration process at the Climate Strategies workshop on Kyoto Implementation (http://www.ukerc.ac.uk/content/view/231/115/). Japanese and Canadian demand potential based upon workshop presentations and subsequent elaboration with respective authors. Kyoto allowance units (AAUs) are only available to governments, not EU ETS industries and the range cited under "low" reflects estimates of the amount likely politically to be offered, which is less than the numerical surplus. (b) Estimates by PointCarbon presented by Kristian Tangen at the PointCarbon Conference, Copenhagen, March 2006 (http://www.pointcarbon.com/Events/Carbon\%20Market\%20Insights/category401.html

* NOTE: The new Canadian government has raised serious questions about its willingness to trade internationally, although it does not have a parliamentary majority anywhere near sufficient to withdraw from the Kyoto Protocol. 
Against this background, our analysis leads to conclusions about phase II allocation in three main areas.

\section{Scale of allocation/cutbacks}

It is fundamental to understanding the EU ETS that the 'caps' combine with 'trading'. Fears that reducing the free allowance allocation would restrain the ability of companies to produce are misplaced: allowances are freely traded, and companies can acquire additional allowances in the market from three different sources. First, some companies may be able to reduce emissions below their allocation and thus sell surplus allowances. Second, the European Commission currently envisages that up to 8\% of allowances can be imported into the European emissions trading scheme from JI and CDM projects. Third, in phase II, governments can auction up to $10 \%$ of all allowances. Cutting back on free allowance allocation does not therefore translate directly into a cutback of feasible emissions or output; it simply helps to establish the price and incentives that companies face to undertake cost-effective emissions abatement. In principle, free allocation is a temporary derogation from bearing the full costs of $\mathrm{CO}_{2}$ emissions.

Recognizing this and the wider context set out above, we reach the following conclusions about phase II allocation.

\section{(i) All sectors should receive less free allowances than projected 'business-as-}

\section{usual' needs}

The evidence that basing allocations on projected 'business-as-usual (BaU)

emissions' leads to an inflation of emission projections is consistent, overwhelming, and readily explicable (see above). The recent market collapse is proof either that 
projections were inflated, or that companies found it far easier than expected to reduce emissions - probably a combination of both.

The psychology of negotiations that give any sector everything that it projects that it would emit, without any $\mathrm{CO}_{2}$ constraint, places an unhealthy emphasis on lobbying around emission forecasts, which are inherently uncertain, and is a fundamentally unsustainable way of approaching allocations in future periods (see below). Moreover, it risks fostering a focus on compliance without optimization, and creates incentives to highlight the difficulties of mitigation rather than to assess objectively the full range of options (Hepburn et al., 2006). A credible case can be made that giving any sector all that it projects would be emitted under $\mathrm{BaU}$ (if defined as if there were no $\mathrm{CO}_{2}$ problem or policy) fundamentally undermines the motivation to cut emissions and could also be challenged under the EC State-aid rules (Johnston, 2006).

Modest cutbacks carry no significant implications for competitiveness. The 'value at stake' involved in a $10 \%$ cutback is about $1 \%$ of present sector value-added for cement and electricity, and around $0.2-0.4 \%$ for steel and refining (Figure 1: see notes on underlying price assumptions). If the companies maximize profits, competitiveness is about their pricing strategy as influenced by the cost of carbon, not by their allocation, and most of these sectors could be expected to continue to profit even under considerably stronger cutbacks (as explained and demonstrated for the core ETS sectors for cutbacks up to 30\% by Smale et al., 2006). In most cases, modest cutbacks would reduce the scale of the profits they can expect to derive as a result of the EU ETS, with no other significant implications for pricing or competitiveness. ${ }^{18}$ 


\section{(ii) Free allocations to the electricity sector should be cut back by more than}

\section{other sectors}

In the light of the scale of profits made by the electricity-generating sector in countries with competitive markets (empirical evidence set out in Sijm et al., 2006), this proposition is now more widely accepted. The electricity sector is barely exposed to foreign competition and, unlike other sectors, it does not face electricity price increases in inputs. In countries with competitive markets, greater cutbacks for the power sector have no direct implications for other sectors, since the price is predominantly set by the opportunity cost of carbon, not by the profit/loss balance of power generators.

Of the total $2.2 \mathrm{Gt} \mathrm{CO}_{2}$ /year emissions covered by the EU ETS overall, the power sector currently accounts for around $60 \%$. To illustrate the potential magnitudes involved, after allowing for forecasting errors: ${ }^{19}$

- $\quad$ a $20 \%$ cutback in free allocations to the power sector would generate a 'potential' demand (i.e. relative to 'no control' emissions with no emissions

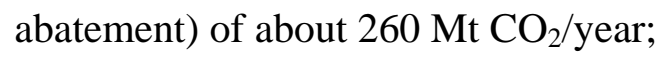

- $\quad$ a 5\% cutback to other sectors on the same basis, about another $45 \mathrm{Mt}$ $\mathrm{CO}_{2} /$ year.

A maximum $10 \%$ of auctioning would make around $210 \mathrm{Mt} \mathrm{CO} /$ year available through auctions, out of a total allocated of $2100 \mathrm{Mt} \mathrm{CO}_{2}$. The overall shortfall - to be met through emissions abatement (e.g. fuel switching end-use efficiency in the power sector) and international purchase - would then still be only around $100 \mathrm{Mt} \mathrm{CO}_{2} /$ year, 
close to the revealed surplus in 2005 and much smaller than the lowest estimates of the total supply of Kyoto project credits.

\section{Method of allocation and new entrant rules}

Allocating allowances for the period 2008-2012 to existing facilities based on historic emissions does not in itself create any adverse incentives. However, if companies expect that the allocation for the period post-2012 will be based on their emissions in the coming years, then this distorts their operational and investment decisions - for example, deterring early action. If free allowance allocation is phased out rapidly post-2012, then this is less of an issue. Otherwise benchmarks based on installed capacity create the fewest distortions. Greater use of benchmarking in individual sectors or countries in phase II could both inform future allowance allocation and signal commitment to these policies.

Giving free allowances to new entrants is being widely considered to help boost new investment, for example to support the security of supply objectives or reduce impacts of $\mathrm{CO}_{2}$ allowance prices on the electricity price. New entrant reserves should be based on output or capacity, and avoid differentiating according to the $\mathrm{CO}_{2}$ intensity of the new investment. In particular, giving more to coal than gas plants rewards investment in new coal facilities, which would conflict with objectives to tackle climate change, increase the cost of future emission reductions, and in the long run could lead to higher electricity prices. The damaging effects would be amplified if carbon-intensive new entrants not only receive free allowances for the period 20082012 but also receive promises for subsequent periods. This could also undermine various options that governments have to implement European and international solutions to address longer-term competitiveness issues and emission spillovers, as discussed below. 
This suggests a sharp contrast between the methods appropriate for incumbents, and those for new entrants. Differentiating allocations to incumbents based on their carbon intensity avoids a large redistribution of rents associated with existing assets; politically, it is unavoidable and does not in itself distort the efficiency of the system, provided the practice is phased out over successive periods. Differentiating allocations to new entrants based on their carbon intensity has no such defence, runs counter to the objectives of the system, and builds up trouble for the future by failing to encourage low-carbon investments.

\section{Price stability and auctioning}

As noted above, there are inherent reasons why the phase II market may be volatile, and price instability carries a cost. Greater stability in price expectations would reduce risks and increase investment in low-carbon technologies and energy efficiency improvements.

The Directive enables allowances to be banked from phase II into future periods. Economic analysis tends to assume that this will improve price stability, by reducing exposure to short-period variations. However, this conclusion depends upon the stability of expectations for future periods. In practice, the early years of phase II may be a period of intense struggle over the shape and degree of future commitments, with considerable impacts on expectations about future emission reductions and allowance prices. Banking may therefore not help to stabilize prices, and could do the opposite. Suggestions that allow 'borrowing' of allowances from future periods would amplify risks and volatility, and introduce additional problems. ${ }^{20}$ Strong intertemporal linkages could also make negotiations about future periods even more political and more complicated, as their impact would be felt directly in the current market. 
Linkages between periods have some desirable features in principle by allowing for longer-term smoothing of demand and supply shocks, but the solutions to price instability lie elsewhere.

Our analysis suggests, rather, that auctions could be employed to improve stability and investor confidence surrounding $\mathrm{CO}_{2}$ prices (Hepburn et al., 2006). The key mechanism would be for governments to release some of their allowances through a joint minimum-price auction. The minimum bid level would then act as a price floor (to the extent that the market needed access to the auction). To avoid competition between Member States, they would have to agree the minimum price and basic auction rules, which could be most simply operated by the European Commission, although Member States would retain the revenues. This process would not conflict with the existing terms of the Directive, and there are several familiar, readily available approaches to conducting such auctions (Hepburn et al., 2006). If the overall allocation is set such that the market requires at least some of these allowances, then this ensures the price will not drop below the agreed minimum bid price. Excessive allocation, or large inflow of cheap allowances from CDM and JI projects, could of course ultimately overwhelm a price floor set in this way, though the 'supplementarity' criteria does also allow member states to limit the inflow into the system (Article 11a of EU Directive on emission trading, amended 27.10.2004) ${ }^{21}$. Some other analysts express the opposite concern, that prices might rise to levels deemed to pose an unacceptable risk to European industry, and that to prevent this risk the system should contain a price cap or ‘safety valve’ (e.g. Bouttes et al., 2006). Our assessment of phase II, in terms of both supply-demand balance and the economics of competitiveness over the 5-year period, leads us to be sceptical that this is a realistic concern. It is, however, true that a planned response to any such 
eventuality would be better than a panic-based reaction such as occurred in the California NOx trading system. Should prices rise to levels that were judged to pose a credible threat to competitiveness of a particular sector, and State-aid rules prevented auction revenues being used to assist it (or the country concerned had not conducted any auctions), the most obvious first step would be to relax supplementarity constraints, and possibly expand the scope of emission credits that could qualify for compliance purposes. We do not consider issues of price ceilings or safety valves beyond this.

\section{B2. Allocation, competitiveness and design post-2012}

As indicated above, early clarity about the existence and nature of the system post2012 would be extremely valuable to the functioning of the EU ETS. Reduced uncertainty post-2012 would enable more efficient investment and thus reduce ongoing $\mathrm{CO}_{2}$ emissions and prices. This will not be easy to achieve.

Negotiations on post-2012 quantified commitments in the framework of the Kyoto Protocol were launched by the Montreal Meeting of Parties in December 2005. Rapid progress is not expected, however, not least because of continued nonparticipation by the USA. The EU ETS Directive is explicitly designed to continue in sequential periods, and the process of examining this in earnest begins with the Review in 2006.

Given the complexity of the issues, combined with the international political situation, a global agreement on post-2012 quantified reduction targets is unlikely before 2009 at the earliest. This is too late to be of much use in assisting efficient investment under the EU ETS: a credible EU commitment and structure to support EU low-carbon investment needs to be established well before then. 
Credibility on post-2012 targets therefore requires clarity and commitment to a design that is:

- $\quad$ effective in reducing $\mathrm{CO}_{2}$ emissions to justify continued policy support

- $\quad$ efficient, for example the structure must achieve acceptably low levels of perverse incentives

- $\quad$ economically sustainable, by avoiding adverse competitiveness impacts and emissions leakage

- $\quad$ politically sustainable, by creating a shared perspective in the public sphere and among key industry sectors that the above objectives are achieved.

The European Emission trading scheme has secured political support for a successful start and the creation of an effective and potentially efficient instrument. After five decades of struggle over European energy and environmental affairs, establishing a free trading market across the EU is no small achievement. It has also secured an environment in which there is now unprecedented management attention devoted to $\mathrm{CO}_{2}$ emissions. However, beyond phase II the EU ETS needs to evolve. Future design needs to avoid the perverse economic incentives that can result from repeated free allowance allocations, and concerns around competitiveness and leakage must be addressed to allow the EU ETS to maintain higher prices over longer periods.

Allocation will in any case have to move away from projection-based approaches for purely pragmatic reasons. Already in phase II negotiations the attempt to estimate 'what emissions would be during 2008-2012 if there were no $\mathrm{CO}_{2}$ policy or problem' requires complex speculation to unravel what may have already been influenced by climate concerns, a year of high carbon prices, the impact of $\mathrm{CO}_{2}$ on gas prices and expectations about the future. After five years of operation and 
investment based on the EU ETS, constructing a 'no carbon policy' projection as a baseline for the post-2012 period would be an exercise in fantastic speculation about precisely which investments might have been 'attributable' to climate policy, and trying to unravel them and guess what might have happened instead, and then project the implications forward. It is a wholly impractical basis for the long term - consistent with the view that phase II is essentially a transitional period towards a bettergrounded and more durable approach.

In principle, the two simplest approaches to maximizing the internal effectiveness and efficiency of the scheme are rapidly to phase out free allocations, or to move to relatively uniform output-based benchmarking of allocations, probably based around the performance of best available technology for the sector.

In either case, the implicit cutbacks probably imply greater use of auctioning. As argued above, this has distributional and State-aid benefits, and could be used in ways that help to stabilize prices, and potentially to support longer term price signalling. This in turn can underpin low-carbon investments directly through greater price security, and also potentially by using auction revenues to support longer term investment instruments (Hepburn et al., 2006).

However, rapidly reducing free allocations may be politically very difficult, and benchmarking is generally far more complex than it appears because of the variety of installation types, processes and products; and neither in itself offers ready protection against competitiveness and leakage concerns. If the EU ETS is to be sustained over long periods, and potentially at high carbon prices, we see three main avenues that have the potential to meet all the criteria: 
- $\quad$ International agreement(s), covering all major competitors, to implement policies that reflect $\mathrm{CO}_{2}$ costs in product prices of energy-intensive, internationally mobile goods. Note that fully global participation may not be required, either in terms of countries or sectors: protecting EU industry under the EU ETS may only require agreement involving the principal competing nations covering the core sectors of aluminium, cement, iron and steel, refineries, and perhaps some chemical products. ${ }^{2122}$ Agreement to reflect $\mathrm{CO}_{2}$ costs in electricity generation would also be desirable because of its downstream impacts. In theory, agreements with sector organizations themselves could be considered, but the absence of any precedents or institutional authorities for such an agreement would make it highly problematic (Kulovesi and Keinänen, 2006). The more serious proposals for sectoral agreements have focused upon governmental commitments, albeit in consultation with their industries (Schmidt and Helme, 2006).

- $\quad$ Use of border-tax adjustments to compensate industry producing in regions with high $\mathrm{CO}_{2}$ costs for these costs when exporting, with a symmetric tariff being applied to imports. Thus the combination of a stringent emissions policy with border tax adjustment does not discriminate against industry in either region (Ismer and Neuhoff, 2004). The flexibility of WTO rules could be explored to ensure that industry in regions controlling $\mathrm{CO}_{2}$ are not disadvantaged, though this would probably require the use of auctioning rather than free allocation to allow compensation for average costs incurred (Hepburn et al., ${ }^{23} 2006$ ). Again, this need not be a universal approach, but rather one addressed to the specific sectors where there may be valid concerns.

- $\quad$ As a fall-back option in case the previous two approaches cannot be implemented, the EU ETS could still be continued by fundamental changes to allow 
output-indexed allocation. Sectors exposed to international competition could receive $\mathrm{CO}_{2}$ allowances in proportion to output (output- or intensity-based allocation). Demailly and Quirion (2006) illustrate how this would avoid both leakage and profiting from the EU ETS by the EU cement industry. The current Directive precludes such allocation (it is a form of ex-post adjustment), for good reasons. Not only would it considerably complicate the system by requiring retrospective adjustments to allocations, it would shield product prices from the real costs of $\mathrm{CO}_{2}$. Along with removing the scope for sectors to profit from the EU ETS price impacts, by removing the costs of $\mathrm{CO}_{2}$ from product prices it would thus remove incentives for product substitution as a means for $\mathrm{CO}_{2}$ abatement. In macroeconomic terms it would thus be less efficient, but it would maintain the incentive for individual sectors to reduce the carbon intensity of their operations, and thus protect the value of lowcarbon investments within the EU ETS sectors whilst avoiding competitiveness problems.

In practice, the EU may not face a straight choice between these three options. Where effective sectoral agreements can be secured, these are probably the best first choice; but they are unlikely to be easy or quick to negotiate, and may come down to focusing on particular products or subsector markets. Border tax adjustments, similarly, are unlikely to be 'all or nothing'. They would instead be considered in the context of particular industries and products, where a valid case for competitiveness concern was raised, and for which other solutions appeared inappropriate. Output-indexed allocations, similarly, could be considered in some cases, but the more widespread their adoption, the more deleterious would be the impact on the macroeconomic efficiency of $\mathrm{CO}_{2}$ controls. 
However, any or all of these options would both avoid competitiveness concerns and protect the security of low-carbon investments in the EU ETS sectors. Thus it is neither possible, nor necessary, for the EU to choose between them now. Rather, our conclusion is that solutions are available, and that the EU can unambiguously commit to continuing the EU ETS, recognizing that three avenues are available to support this decision in the event of failure to secure a truly global agreement. The next few years can then be used to engage industry and other stakeholders in dialogue about which would be the most appropriate avenue to follow, perhaps on a case-by-case basis, given the limited number of sectors at stake.

\section{B3. Implications of post-2012 options for phase II and the Directive}

We conclude our analysis by considering briefly the implications of this analysis in relation to phase II, the EU ETS Directive, and related institutional considerations. All three of the options above for long-term design would probably require amendments to the EU ETS Directive, or other complex bodies of EU legislation:

- $\quad$ in the case of international sectoral agreements, to accommodate the specifics of such agreements

- $\quad$ in the case of border tax adjustments, to implement the necessary tariff legislation

- $\quad$ in the case of output-indexed allocation, to enable ex-post adjustment conditional upon industry output. 
These observations raise the question of whether such measures, and associated amendment, should be considered for phase II. We unambiguously conclude not, for two strong reasons.

First, the economic analysis in our studies underlines that competitiveness is primarily a strategic issue, not an immediate one. Most participating sectors can expect to profit from the EU ETS in phase II: but those for which this involves significant price rises on internationally traded products may start to see erosion of exports, and/or import penetration into domestic markets, if product price impacts are high enough and sustained (Demailly and Quirion, 2006; Smale et al., 2006). Similarly, decisions on the location of major investment by multinational companies will not be made primarily on the basis of carbon costs to 2012: they will be based on strategic evaluation of the costs and benefits of locating in different regions over periods of decades (Grubb et al., 2006). Indeed, phase II could be considered as a transitional period in which the profits accruing to several sectors as a result of free allocations could be used to build up investment in low-carbon technologies and associated expertise, enhancing their position for a carbon-constrained world. Second, the changes that may be required for post-2012 continuation are all complex. Sectoral agreements would require extensive international negotiation; so, in practice, would any sensible approach to border tax adjustments. Even output-indexed allocation would require extensive redesign of trading markets and evaluation of the appropriate basis to be used. Moreover, the sectors are not homogeneous and the EU does not have homogeneous industries; on the contrary, diversity of products, processes, and national circumstances is the norm when these sectors are examined more closely (Grubb et al., 2006). Any attempt to reopen the Directive to make such adjustments quickly for phase II would rapidly risk unravelling. The only possible 
exception might be for adjustments driven by, and confined to, the explicit legal basis of State-aid considerations - which itself allows for the continuation of existing arrangements while alternatives are developed (Johnston, 2006).

Indeed, the relative simplicity of the system as it stands, and the flexibility it gives to Member States, should to some degree be considered as an opportunity for experimentation. For example, benchmarked allocations in a range of sectors may be an attractive approach for the longer term; but this is far from certain, given the complexities. If phase I was mainly about establishing the market, phase II offers the chance for national experimentation with some of these allocation possibilities. There is one significant caveat to this. Allocations during phase II should not create promises about allocations post-2012 that foster inefficiency, or undermine the options post-2012. The risk of perverse incentives arising from expectations about continued free allocation has already been illustrated (and detailed in Neuhoff et al., 2006). Moreover, WTO law (and arguably EC State-aid law) may allow border tax adjustments that compensate for actual costs incurred, but not for opportunity costs; consequently they may be most effective in combination with very limited or no free allowance allocation. Output-indexed allocation might offer free allowances, but not against a historic baseline or an ex-ante commitment. For phase II this is relevant if countries make promises about future allocations, for example in the context of new entrants. This not only risks the distortions already indicated; it could also undermine Europe's scope to evolve the EU ETS to a system that uses sound economic principles to secure efficient emission reductions whilst avoiding competitiveness distortions. Finally, managing the future allocation of allowances, which will be increasingly valuable at higher carbon prices over time, will require stronger institutional foundations. Allocations designed to compensate sectors for average costs incurred 
would require far more sophisticated approaches than are currently being considered, which might have to be differentiated much more according to specific sectoral characteristics. Long-term credibility is crucial; yet greater sectoral differentiation of approaches could make it even harder to resist pressures to tweak allocations for short-term political convenience. There may also be more need to harmonize allocation methods across Europe. Faced with these conflicting pressures, governments may need to learn from monetary policy, in which the need for credibility of commitments to tackle inflation led to the establishment of independent central banks with clear mandates, and ultimately the creation of the European Central Bank. Establishing a long-term, clear and credible foundation for allocating allowances under the EU ETS, and managing its diverse international linkages, could require thinking of a similar order.

The EU ETS is a remarkable achievement. Current debates, in the light of the first verification results, the allocations for phase II, and the launch of the Review for phase III, offer important windows of opportunity to improve the scheme for both phase II and beyond. Member States need to look beyond the immediate short-term pressures of allocation negotiations, and seize the opportunities on offer. 
Acknowledgements:

Climate Strategies would like to express its sincere gratitude to the following organisations for sponsoring and supporting this study: TSEC; Department of Trade and Industry, UK; Department for Environment, Food and Rural Affairs, UK; The

Carbon Trust; Ministry of Economy, Netherlands; BP; and the Ministry of Sustainable Development, Sweden.

For more information about Climate Strategies, the EU Emissions Trading Scheme study and work on national implementation, contact: Beverley Darkin, Convenor, Climate Strategies \& Senior Research Fellow, Chatham House, bdarkin@chathamhouse.org.uk, Tel: + 44 (0)20 79575741.

\section{References in Climate Policy Special Issue, Volume 6(1): Allocation and Competitiveness in the EU ETS}

Demailly, D., Quirion, P., 2006. $\mathrm{CO}_{2}$ abatement, competitiveness and leakage in the European cement industry under the EU ETS: grandfathering versus outputbased allocation. Climate Policy 6(1).

Hepburn, C., Grubb, M., Neuhoff, K., Matthes, F., Tse, M., 2006. Auctioning of EU ETS phase II allowances: how and why? Climate Policy 6(1).

Johnston, A., 2006. Free allocation of allowances under the EU emissions trading system: legal issues. Climate Policy 6(1).

Neuhoff, K., Keats, K., Sato, M., 2006. Allocation, incentives and distortions: the impacts of EU ETS emissions allowance allocations to the electricity sector. Climate Policy 6(1).

Sijm, J.P.M., Neuhoff, K., Chen, Y., 2006. $\mathrm{CO}_{2}$ cost pass-through and windfall profits in the power sector. Climate Policy 6(1).

Smale, R., Hartley, M., Hepburn, C., Ward, J., Grubb, M., 2006. The impact of $\mathrm{CO}_{2}$ emissions trading on firm profits and market prices. Climate Policy 6(1).

\section{Other references}

AEA Technology Environment, Ecofys UK, et al., 2006. A report produced for the LETS Update Partners [retrieved 26 May 2006, from 
http://www.environmentagency.gov.uk/business/444217/590750/590838/1294204/1295326/1291719/1 291949/?version=1\&lang=_e].

Baldursson, F.M., von der Fehr, N.-H.M., 2004. Price volatility and risk exposure: on market-based environmental policy instruments. Journal of Environmental Economics and Management 48(1), 682-704.

Bouttes, J.-P., Leban, R., Trochet, J.-M., 2006. A Low Carbon Electricity Scenario: A Contribution to the Energy Policy and Climate Change Debate. DDX-06-10. del Rio Gonzalez, P., 2006. Harmonization versus decentralization in the EU ETS: an economic analysis. Climate Policy 6, forthcoming.

Carbon Trust, 2004. The European Emissions Trading System: Implications for Industrial Competitiveness, Carbon Trust, London [available at http://www.carbontrust.co.uk/default.ct].

EC, 2005. Further Guidance on Allocation Plans for the 2008 to 2012 Trading Period of the EU Emission Trading Scheme. European Commission, Brussels.

Grubb, M., Azar, C., Persson, U.M., 2005. Allowance allocation in the European emissions trading system: a commentary. Climate Policy 5(1).

Grubb, M., Sato, M., Cust, J., Chan, K.L., Korppoo, A., Ceppi, P., 2006. Differentiation and dynamics of competitiveness impacts from the EU ETS. Climate Policy 6, forthcoming.

Ismer, R., Neuhoff, K., 2004. Border Tax Adjustments: A Feasible Way to Address Nonparticipation in Emission Trading. Cambridge Working Papers in Economics, CWPE 0409. 
Kulovesi, K., Keinänen, K., 2006. Long-Term Climate Policy: International Legal Aspects of a Sector-based Approach. Finnish Environment Ministry [available at http://www.ymparisto.fi/download.asp?contentid=29397\&lan=fi].

Schleich, J., Betz, R., 2004. EU Emissions trading and transaction costs for small and medium sized companies. Intereconomics/Review of European Economic Policy 39(3), 121-123.

Schmidt, J., Helme, N., 2006. Sector-based approach to the post-2012 climate change policy architecture. Climate Policy 6, forthcoming. 
${ }^{1} 1 . \mathrm{CO}_{2}-2.2$ billion tonnes of annual $\mathrm{CO}_{2}$ emissions in phase I (EC, 2005), at prices between $€ 10$ to $€ 30 / \mathrm{tCO}_{2} . \mathrm{SO}_{2} 10 \mathrm{mil}$ t at $\$ 270-850 /$ short ton, NOx East Coast, 640,000 t at \$2000/short ton.

${ }^{2}$ Note that this is a complementary treatment to that presented in the Carbon Trust analysis (Carbon Trust, 2004) which focused on the variation in value at stake for a range of electricity price passthrough and a modest range of allocation cutbacks $(0-10 \%)$. The intent in Figure 1 is also to give an insight into the marginal cost impacts that can drive imports under profit-maximizing behaviour. In addition, the chart in Carbon Trust (2004) was indexed on total sector turnover, rather than value-added. ${ }^{3}$ If the marginal carbon intensity equals the average carbon intensity, the MVAS as indicated here is equal to the marginal cost divided by the sector value-added per unit output. In most sectors, in most countries, there is not much divergence between the marginal and average carbon intensity.

${ }^{4}$ Sectors outside of the EU ETS would face the cost impact at the bottom of each bar (electricity price exposure) and an equivalent incentive to change the price of their products; there would be no divergence between average and marginal/opportunity costs, and no resulting scope for profiting from such divergence.

${ }^{5}$ Based on preliminary data from the EC for verified emissions for 21 of the 25 countries covered by the EU ETS, released on 15 May 2006. It is assumed that Poland, the main unknown, has an 18\% excess allocation, similar to Hungary and the Czech Republic. The data suggest that market was $86 \mathrm{MtCO}_{2}$ (long) in 2005. See the article on auctioning (Hepburn et al., 2006).

${ }^{6}$ And indeed had been predicted on the basis of simple aggregate trend statistics and the experience with previous target-based systems such as the UK ETS and Climate Change Agreements (Grubb et al., 2005).

${ }^{7}$ This is for three reasons. First, business, like the rest of humanity, tends towards optimism. No business sets out its store based upon pessimism, contraction, or projected failure. Second, linking allocations to projected needs creates a huge incentive for businesses to inflate forecasts. Third, assumptions that cutting emissions would take time and capital underestimate the scope for some basic housekeeping measures: companies 'don't know what they don't know' about mitigation possibilities until they find out.

${ }^{8}$ These are classic results of real option theory. See Baldursson and von der Fehr (2004) for a more sophisticated discussion of this issue.

${ }^{9}$ Obviously industry is exposed to volatile prices for many other input factors, but if all producers use similar technologies, then they can pass on changes in input prices to product prices. In contrast, if two competing technologies, e.g. with different levels of energy efficiency, can be used to manufacture the same product, then cost differences that only affect one technology are more difficult to pass to the product price. Risk-averse investors then prefer the solution with lower capital costs - which is usually not the energy-efficient approach. Reducing uncertainty about post-2012 can thus accelerate investment in low-carbon technologies, reducing emissions and $\mathrm{CO}_{2}$ allowance prices.

${ }^{10}$ In these countries, domestic bills are not affected despite an increase in wholesale price levels, and the vertically integrated companies cross-subsidize their retail costs with the profits from the free allocation. In other countries, dominant power generators might anticipate government intervention and thus refrain from passing on $\mathrm{CO}_{2}$ opportunity costs to wholesale price levels.

${ }^{11}$ The amounts available in most allocation plans are limited, and the response of new construction too slow; and once operational, carbon-intensive new entrants face the same incentive as incumbents to factor-in opportunity costs of production.

${ }^{12}$ Of course, discouraging closure might be considered as an aim of policy, particularly in the power sector, where many European countries are worried about adequacy of generating capacity. But it is using the ETS for purposes - to implicitly support extending plant lifetimes - contrary to that for which it was designed, and such extension could be at the expense of new investment in lower emitting plant. ${ }^{13}$ The modelling studies of Neuhoff et al. (2006) include an example where technology-specific new entrant reserves, extended into technology-specific incumbent free allocations in future periods, result in coal plants being constructed that would not have been economic in the absence of the EU ETS.

${ }^{14} \mathrm{An}$ allocation that is not differentiated between different fuel types (uniform benchmark, outputbased) reduces opportunity costs of emitting $\mathrm{CO}_{2}$ and thus reduces the impact on the product price. This reduces incentives to substitute less $\mathrm{CO}_{2}$-intensive products, e.g. from cement to wood as a building material, or from electricity consumption to investment in energy efficiency. If such 'outputbased updating' allowance allocation is differentiated between production processes and fuel types, then additional distortions create an incentive to increase operation of more $\mathrm{CO}_{2}$-intensive fuels and production processes. 


\footnotetext{
${ }^{15}$ See also the forthcoming ECP Report No. 2: The EU ETS: Taking Stock and Looking Ahead [available at http://www.ceps.org/].

${ }^{16}$ This issue was a major focus of the LETS study, 'LIFE Emissions Trading Scheme' (AEA
}

Technology Environment, Ecofys UK et al., 2006). This concluded that the EU ETS coverage could readily be expanded to include $\mathrm{CO}_{2}$ from some chemical sectors (production of ammonia, fertilizers and petrochemicals); methane from coal mines; and $\mathrm{CO}_{2}$ and PFCs from aluminium production. These would increase emissions coverage of the EU ETS by about 9\%, resulting in it covering almost exactly half of EU total $\mathrm{CO}_{2}$ emissions. Overall, however, 'there is limited scope for modifying the current Directive to include additional sectors and gases in the scheme for practical reasons. Many sectors either consist of a large number of small emitters or their emissions are too uncertain. Other measures may be more appropriate for tackling emissions from these sectors.'

${ }^{17}$ Whilst the wider political debate is calling for more sources (such as aviation) to be included, the debate within the EU ETS is about precisely the opposite: whether the $20 \mathrm{MW}$ threshold for small facilities has been set too low, causing high administrative costs across thousands of installations that contribute only a small fraction of the total emissions covered (e.g. Schleich and Betz, 2004).

${ }^{18}$ The only exception would be where energy-intensive operations engage in 'limit pricing' designed explicitly to exclude foreign competition in the most exposed markets, rather than seeking to maximize overall profits, i.e. where companies are already cross-subsidizing operations to exclude cheaper imports. Even cement, with by far the highest relative 'value at stake', the magnitudes are not large compared with the present costs and with integrated cement companies, the profits accruing to the more shielded inland cement operations would more than fund continuation of such cross-subsidy if the companies choose to adopt that strategy over the phase II period (see Demailly and Quirion, 2006).

${ }^{19}$ If the upward bias of aggregate forecasts over the period were estimated to be $5 \%$, for example, the corresponding cutbacks relative to these forecasts would be about $25 \%$ and $10 \%$, respectively.

${ }^{20}$ In addition to uncertainty about future prices, this would inject into the phase II market uncertainties about the terms of borrowing from future periods that do not yet exist, against allocations that are not yet defined, with no legal clarity around penalties for non-compliance in future periods, and with much scope for lobbying future allocations based upon the size of the 'debt' accumulated.

${ }^{21}$ For example, the German draft NAP2 allocation plan indicates a limit on imports of $12 \%$ of allocation (Draft NAP, and statement by Jurgen Landgrebe indicating he expected this limit to remain, cited in Point Carbon 02 June 06.

${ }^{22}$ Nor, in fact, is the converse true: a global agreement on national $\mathrm{CO}_{2}$ targets would not necessarily protect industrial competitiveness, if other countries sought to meet their targets through action on domestic or transport sectors whilst still protecting their internationally mobile industries from $\mathrm{CO}_{2}$ costs. This further strengthens the case for designing the ETS to be viable for the long term in ways that do not hinge upon an all-encompassing global agreement. 